\title{
Research on real time interactive price of highway charging stations based on energy-carrying by EVs
}

\author{
Jun Cheng ${ }^{a}$, Xueliang Huang ${ }^{b}$, Zhong Chen ${ }^{c}$ and Yu Jing ${ }^{d}$ \\ School of Electrical Engineering, Southeast University, Nanjing 210000, China \\ achengjunseu@126.com, ${ }^{b} x$ lhuang@seu.edu.cn, ${ }^{c}$ zhongchen@seu.edu.cn, ${ }^{d}$ bournejing@163.com
}

Keywords: EV, New energy, Electricity price, V2G, energy-carrying by EVs.

\begin{abstract}
This paper presents real time interactive price scheme of highway charging stations based on energy-carrying by Evs. Construct the optimization model to minimize the time-space variance of power grid equivalent load, calculate and release the price before day; in order to reduce the load of conventional and new energy output prediction error of conventional units, and reoptimize the charging power of the electric vehicles. The calculation example shows that: The proposed real time pricing can not only lead the electric vehicle charging behavior in the highway more effectively, but also improve the operation economy of power network in access to newenergy at the same time.
\end{abstract}

\section{Introduction}

As the main power of renewable energy, wind power has become the hot spot of domestic and foreign research.. The output of wind power is fluctuating and random.,large scale wind power access will bring the power grid operation and control difficult. Sometimes there will inevitably be aban-doned wind behavior. The development of electric vehicles attach great importance by many countries in recent years and scale development will have an impact on the normal load characteristic, how to order charging for the acceptance of grid scheduling is worthy of research directions [1-2]. Literature [3] to increase the absorptive capacity of the wind power established multi time scale of electric vehicles-wind power cooperative scheduling mathematical model, analyze the feasibility of smoothing grid equivalent load fluctuation and absorb night excess wind power by scheduling the electric vehicle charging, but they do not consider the V2G function of electric cars. Document [4] to establish the electric vehicle charging multi-objective mixed integer nonlinear optimization scheduling model, using fuzzy set theory, convert multiple targets to single targets base on fuzzing about the output power from wind and solar, and solve the problem by the PSO algorithm. The current work is based on electric vehicle direct control by the dispatching institution, but consider to the number of future system in electric vehicles can be very large the scheduling feasibility may be a problem. Another feasible idea is that the dispatching mode is reflected by electricity price, and the user is based on electricity price incentive auto response scheduling [5].

\section{Load Model Of Electric Car Charging Stations}

\subsection{Time-space Distribution and Speed of Vehicles.}

Based on the investigation and analysis results about highway traffic by US department of transportation, due to the different traffic densities, highway traffic meet different probability distribution [6]. The following is a basic two highway traffic probability distribution:

1) Poisson Distribution

$P_{k}=\frac{(\lambda t)^{k}}{k !} e^{-\lambda t}$

Apply: Traffic density is not great, that traffic is a random case. Wherein, $\mathrm{P}_{\mathrm{k}}$ : the probability of $\mathrm{k}$ vehicles arrived in the count interval $(\mathrm{t}) ; \lambda$ : The average arrival rate (vehicle/s); $t$ : Duration of each counting interval(s).

2) Binomial Distribution 


$$
P_{k}=C_{n}^{k}\left(\frac{\lambda t}{n}\right)^{k}\left(1-\frac{\lambda t}{n}\right)^{n-k}, k=1,2, \cdots, n
$$

Apply: Traffic density is great, the traffic flow of few opportunities to freely drive. Wherein, the para- -meters are same as above.

In the highway range, similar to conventional fuel vehicles, traveling speed of electric vehicles ( $\mathrm{V}_{\text {speed }}$ ) obey average distribution of $90 \sim 120 \mathrm{~km} / \mathrm{h}$.

\subsection{Habits of Private Electric Vehicles Owners in Highway.}

In this paper, do the following assumptions for electric car driving habits in highway.

1) The battery capacity of electric vehicles $\left(C_{\text {battery }}\right)$ obey the average distribution of $50 \sim 70 \mathrm{~kW} \bullet \mathrm{h}$, the average energy consumption is $\mathrm{W}=0.20 \mathrm{~kW} \cdot \mathrm{h} / \mathrm{k} \mathrm{m}$;

2) The Charging power of charging station in highway $\left(\mathrm{P}_{\text {charge }}\right)$ is $120 \mathrm{~kW}$, the charging efficiency $(\eta)$ is 0.95 ;

3) The SOC of electric vehicles' battery in highway meet normal distribution $N(0.6,0.12)$;

4) Consider the life of electric vehicle battery and charging efficiency, the SOC of electric vehicles' battery maintained between $10 \%$ and $90 \%$.

\subsection{Mobile Energy Carring Model of Highway.}

Forced Energy Carrying.

In this article, when electric car reach the charging stations (i) in highway, because SOC below a certain set value, so electric car must be recharged, therefore the charging load generated in charging station is defined as forced energy carrying.

$$
\left\{\begin{array}{l}
A^{i}=\sum_{j=1}^{n} S_{j}\left(S O C_{j}^{\max i}-S O C_{j}^{\min i}\right) \\
S O C_{j}^{\min i}=S O C_{j}^{o}-\mu(v) L_{o i} / S_{j}
\end{array}\right.
$$

Wherein: $\operatorname{SOC}_{j}^{\text {lim }} \leq \operatorname{SOC}_{j}^{\text {min }} \leq \operatorname{SOC}_{j}^{\text {set }}, i \in \Pi$ is a set of EVs; $v(\Delta t)$ :is average driving speed of the vehicle in each time period $(\Delta t)$.

Willingness Energy Carrying.

In this article, when electric car reach the charging stations (i) in highway, The SOC of electric vehicles is in the interval which he can choose or not choose to charge, if the owners choose to charge behavior, therefore the charging load generated in charging station is defined as willingness energy carrying.

$$
\left\{\begin{array}{l}
\kappa=P\left(k_{1}, k_{2}, \cdots, k_{m}\right) \\
B^{i}=\sum_{j=1}^{n} S_{j}\left(S O C_{j}^{\max i}-S O C_{j}^{\min i}\right) \\
S O C_{j}^{\min i}=S O C_{j}^{o}-\mu(v) L_{o i} / S_{j}
\end{array}\right.
$$

Wherein: $\mathrm{SOC}_{\mathrm{j}}^{\text {set }} \leq \mathrm{SOC}_{\mathrm{j}}^{\mathrm{min}} \leq \mathrm{SOC}_{\mathrm{j}}^{\text {wish }}, i \in \Pi$ is a set of EVs; $\mathrm{v}(\Delta \mathrm{t})$ : is average driving speed of the vehicle in each time period $(\Delta \mathrm{t}) . \kappa$ is user response factor.

\section{Best Price Solving Model}

\subsection{The Price Before Day.}

The Objective Function.

In this paper, the optimization goal is keep time- space variance of power grid equivalent load minimum:

$$
F_{1}=\min \left[\sum_{i=1}^{N} \frac{\omega_{i}}{N} \sqrt{\sum_{t=1}^{T}\left(L_{d}(i, t)-P_{W, d}(i, t)+P_{s, d}(i, t)-P_{A V}(i)\right)^{2}}\right]
$$

Among them,

$$
P_{A V}(i)=\frac{1}{T} \sum_{t=1}^{T}\left(L_{d}(i, t)-P_{W, d}(i, t)+P_{s, d}(i, t)\right)
$$


Wherein,t $\in 1,2, \ldots, \mathrm{T} ; \mathrm{T}$ is the number of hours in the study period, this article take 24 ; $\mathrm{i} \in$ $1,2, \ldots, \mathrm{N} ; \mathrm{N}$ is the number of charging stations of electric vehicles in highway net under study,this article take 30; $\mathrm{L}_{\mathrm{d}}(i, t) / \mathrm{P}_{\mathrm{W}, \mathrm{d}}(i, t) / \mathrm{P}_{\mathrm{s}, \mathrm{d}}(i, t)$ is the forecast value before day of conventional load/ wind power/ the total charge power for electric vehicles; $\omega$ i is the influence factor of the highway network's charging station load on the power grid.

Restriction Condition.

Restriction conditions should include: 1) the optimization power of charging station in highway should be higher than the energy of forced energy carrying and lower than the total energy of forced energy carrying and willingness energy carrying; 2) the optimization power of charging station in highway should be sure to in the range of site service ability (without considering equipment status), expressed as follows:

$$
\left\{\begin{array}{c}
P_{c, d}^{q z}(i, t) \leq P_{c, d}(i, t) \leq P_{c, d}^{q z}(i, t)+P_{c, d}^{y y}(i, t) \\
0 \leq P_{c, d}(i, t)+P_{n c, d}(i, t) \leq N_{c h a r g e}(i) * P_{\text {charge }} / \eta
\end{array}\right.
$$

Wherein, $\mathrm{P}_{\mathrm{c}, \mathrm{d}}(i, t)$ is the optimized Charging power about the electric car who participate schedule in highway; $\mathrm{P}_{\mathrm{nc}, \mathrm{d}}(i, t)$ is the predictive value about the electric car who don't participate schedule in highway before day; $\mathrm{P}_{c, \mathrm{~d}}^{\mathrm{qz}}(i, t)$ is the predictive value about the energy of forced energy carring before day; $\mathrm{P}_{c, d}^{\mathrm{yy}}(i, t)$ is the predictive value about the energy of willingness energy carring before day; $\mathrm{N}_{\text {charge }}(i)$ is the number of charging facilities at charging station i in highway.

Price Calculation.

After obtained charging power in highway by optimization, according to formulas (8) (11) calculate the price before day. The matrix which reflect the change in consumption caused by the price change is called the price elasticity coefficient matrix $E_{\text {price }}$, the formula is as follows:

$$
\begin{aligned}
& \Delta P_{c, d}^{t}=E_{\text {price }}^{t} * \Delta Q_{c, d}^{t}+E_{\text {price }}^{t-1} * \Delta Q_{c, d}^{t-1}+E_{\text {price }}^{t+1} * \Delta Q_{c, d}^{t+1} \\
& \Delta P_{c, d}^{t}=\left[\begin{array}{l}
\Delta P_{c, d}(1, t) \\
\Delta P_{c, d}(2, t) \\
\vdots \\
\Delta P_{c, d}(N, t)
\end{array}\right] \Delta Q_{c, d}^{t}=\left[\begin{array}{l}
\Delta Q_{c, d}(1, t) \\
\Delta Q_{c, d}(2, t) \\
\vdots \\
\Delta Q_{c, d}(N, t)
\end{array}\right] \\
& E_{p r i c e}^{t}=\left(\begin{array}{ccc}
\varepsilon_{1,2}^{t} & \cdots & \varepsilon_{1, N}^{t} \\
\vdots & \ddots & \vdots \\
\varepsilon_{N, 1}^{t} & \cdots & \varepsilon_{N, N}^{t}
\end{array}\right) \\
& P_{A V}(i)=\frac{1}{T} \sum_{t=1}^{T}\left(L_{d}(i, t)-P_{W, d}(i, t)+P_{s, d}(i, t)\right)
\end{aligned}
$$

Wherein, $\Delta \mathrm{P}_{\mathrm{c}, \mathrm{d}}(\mathrm{i}, \mathrm{t})$ is the adjustment value of optimized Charging power's about the electric car who participate schedule in highway before day; $\Delta \mathrm{Q}_{\mathrm{c}, \mathrm{d}}(\mathrm{i}, \mathrm{t})$ is the adjustment value of optimized Charging price about the electric car in highway before day.

\subsection{Solving the Price before Day by Optimization Algorithm.}

In program, individual chromosome is charging power of all electric car charging stations in highway, adopt genetic algorithms to optimize, get the each node's equivalent load curve before and after optimization in grid. Among them select the algorithm parameters as follows: initial population size is 50; maximum hereditary algebra is 5000 times; Crossover probability is 0.8; Mutation probability is 0.02. Algorithmic process shown in Figure 1. 


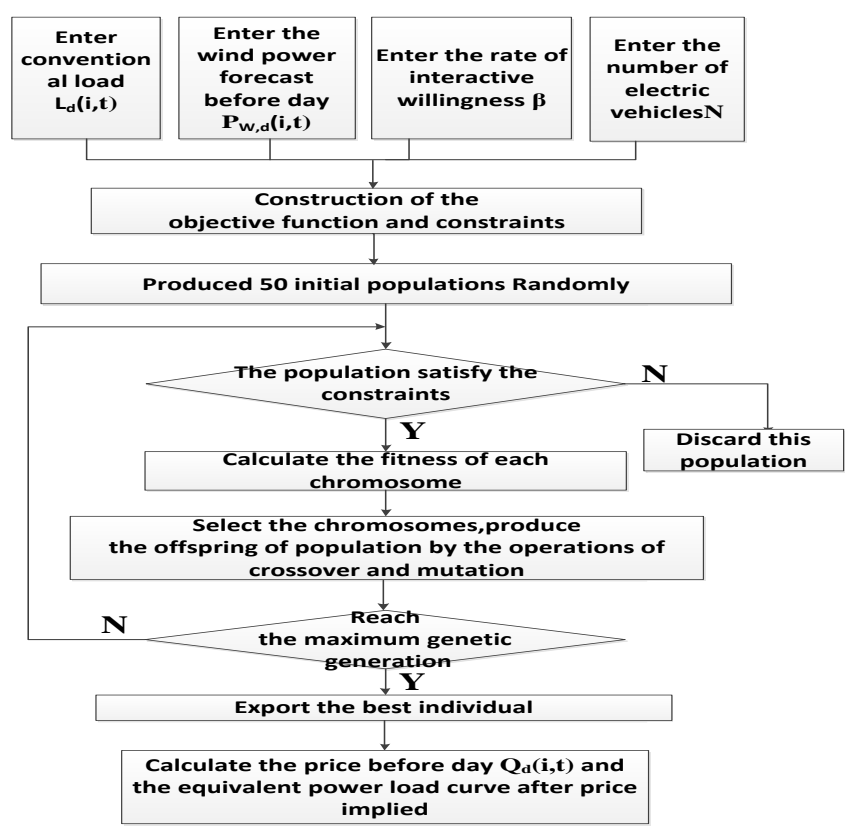

Figure 1 Solving process of price before day

\subsection{The Price before Hour.}

The Objective Function.

In this article, at period ( $t$-1) forecast conventional load/new energy output and traffic flow of period t by neural network method. This paper considers in a certain time window, compensate the difference between predicted value before day and predicted value before hour about conventional load and new energy output by optimizing the charging power in highway, make the sum's absolute value of the prediction error and charging electric power variation amount, and make each Charging power match the service capacity of the charging station (related to device status etc.). The objective function show as the formula (12):

$$
F_{2}=\min \left[\sum_{i=1}^{N} \omega_{i}\left(\sum_{t=T-M+1}^{T}\left|\Delta L_{h}(i, t)-\Delta P_{w, h}(i, t)+\Delta P_{s, h}(i, t)\right|\right)\right]
$$

Wherein, $\mathrm{M}$ is the number of time window, $0<\mathrm{M} \leq \mathrm{T} ; \mathrm{P}_{\mathrm{s}, \mathrm{h}}(i, t)$ is the charging power optimization value in the second Optimization; $\mathrm{L}_{\mathrm{h}}(i, t)$ is the predicted value before hour of conventional load; $\mathrm{P}_{\mathrm{w}, \mathrm{h}}(i, t)$ is the predicted value before hour of new energy output.

Constraints.

The constraints is similar to the constraints what used in the price calculating before day, The only difference is to consider the service capacity factor of each charging station additionally, as formula (13) below. Restriction conditions should include:1) the optimization power of charging station in highway should be higher than the energy of forced energy carrying and lower than the total energy of forced energy carrying and willingness energy carring;2) the optimization power of charging station in highway should be sure to in the range of site service ability (with considering equipment status), expressed as follows:

$$
\left\{\begin{array}{c}
P_{c, h}^{q z}(i, t) \leq P_{c, h}(i, t) \leq P_{c, h}^{q z}(i, t)+P_{c, h}^{y y}(i, t) \\
0 \leq P_{c, h}(i, t)+P_{n c, h}(i, t) \leq\left(N_{\text {charge }}(i)-N_{\text {charge }, h}^{\text {fault }}(i)\right) * P_{\text {charge }} / \eta
\end{array}\right.
$$

Wherein, $\mathrm{N}_{\text {charge, }}^{\text {falt }}(i, t)$ is the number of charging facilities in faults.

\subsection{Solving Process of the Price before Hour.}

Treat the price before day and the predicted value before day about conventional load and new energy output as input for solving the price before hour. At moment $t-1$, forecast the conventional load and new energy output of period $t$ by neural network method, re-optimize the charging power of charging stations about period t, and re-compute the price before hour. The process shown in Figure 2. $\mathrm{Q}_{\mathrm{d}}$ is the price before day, $\mathrm{Q}_{\mathrm{h}}$ is the price before hour. 


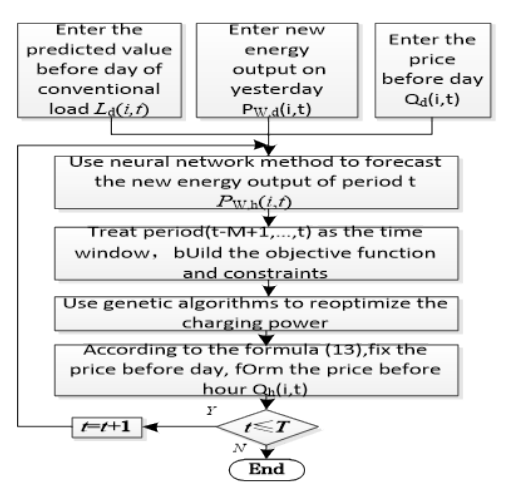

Figure 2 Solving process of price before hour

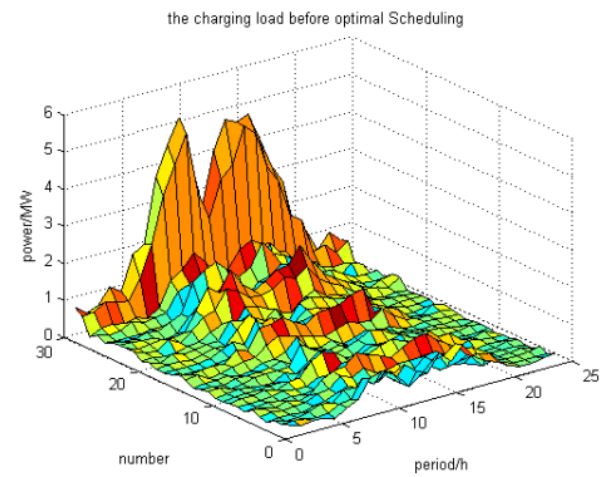

Figure 3: the Charging load before optimal scheduling

\section{Simulation Example}

To verify the optimization model in this paper, Basis on the high-speed traffic topology of Jiangsu Province, Analysis geographical spatial correlation about each charging station. Use the typical daily load data of a region as base load, related parameters about EVs charging are as follows: $\mathrm{N}=20000, \beta=0.90$, Reference price $\mathrm{Q}_{\mathrm{ck}}=1.5 \mathrm{yuan} / \mathrm{kW} \cdot \mathrm{h}, \varepsilon=-0.50$. And assuming that in the case of the implementation of the price scheme, owners can respond to price in real time, that is representing electric vehicle charging power can reach calculated charging power after optimization. Obtained the charging load before optimal Scheduling of 30 charging stations and 24 hours as shown in figure 3. Its space-time variance is: 47.67.

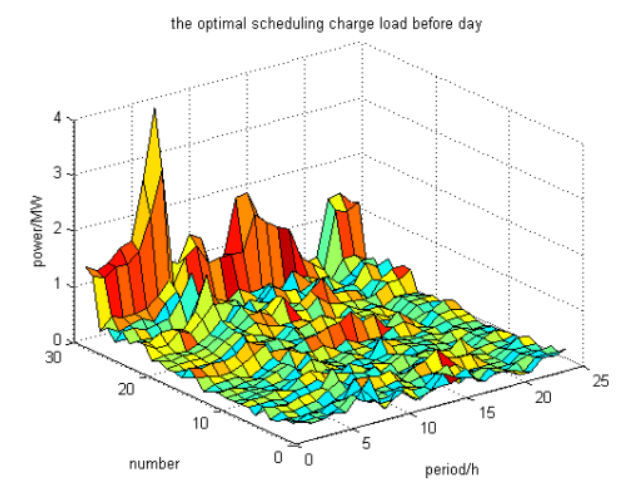

Figure 4: the Optimized charge load before day

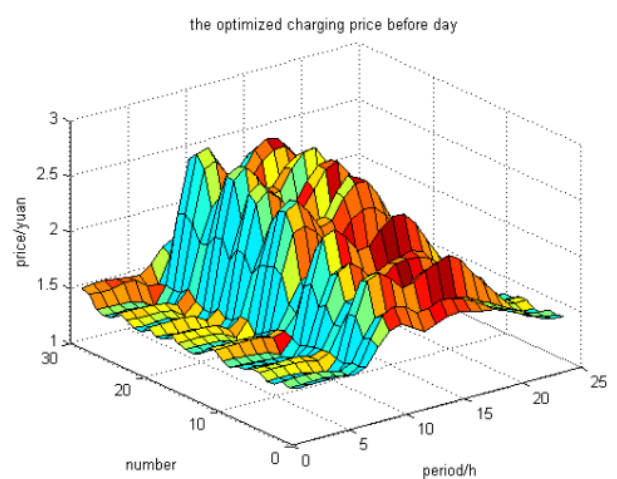

Figure 5: the Optimized charging price before day Use the optimal scheduling model in this article to obtaine the optimal scheduling charge load before day (as Figure 4) and to develop the corresponding optimized charging price before day(as Figure 5). Including conventional load,new energy output and optimized charge load, make the time-space variance of the total load about each site and each period drops to 38.20.

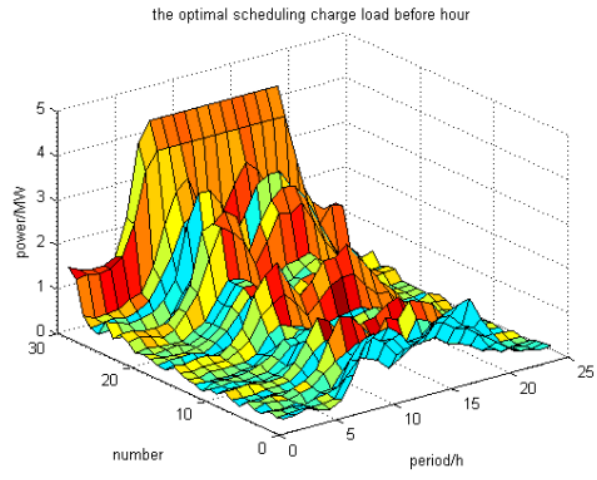

Figure 6: the Optimized charging load before

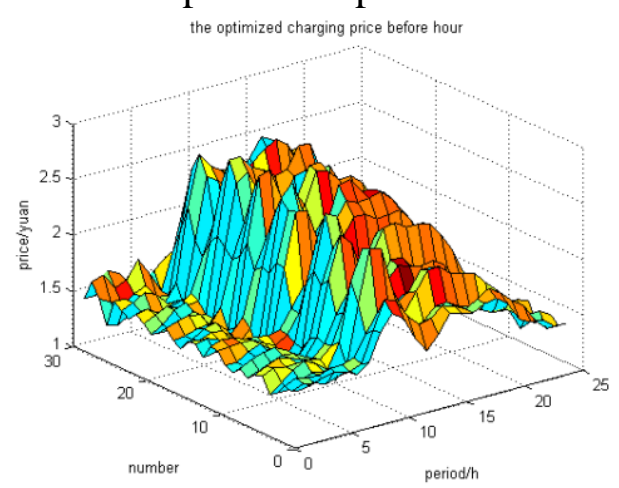

Figure 7: the Optimized charging price before hour 
Since the presence of forecast error about conventional load and new energy output, If dispatch the charging load by the optimized charging load before day, the time-space variance of the total load increases to 45.72. Use the optimal scheduling model in this article to obtaine the optimal scheduling charge load before hour (as Figure 6) and to develop the corresponding optimized charging price before hour(as Figure 7). Including conventional load,new energy output and optimized charge load, make the time-space variance of the total load about each site and each period drops to 38.04.

\section{Summary}

Show as the example verification,in the case of the implementation of real-time price, the scheduling mechanism can adjust the charging station load by scheduling the charging behavior of EVs user in highway, While access to new energy sources,improved the running economy of grid, and reduced the impact on the grid economy from the randomness of new energy output, Form the complementary between new energy output and electric vehicle charging load, improve power system's capacity about receiving new energy and electric vehicle charging load.

\section{Acknowledgments}

This work was supported by State Grid Corporation of China.

\section{References}

[1]. WANG Guibin, ZHAO Jun hua, WEN Fu shuan, et al. Stochastic optimization dispatching of plug-in hybrid electric vehicles in coordination with renewable generation in distribution systems [J] .Automation of Electric Power Systems,2012,36(19):22-29.

[2]. Yang H, Lu L, Zhou W.A novel optimization sizing model for hybrid wind power generation system [J]. Solar Energy,2007,81(1): 76-84.

[3]. ZHAO Junhua WEN Fushuan XUE Yusheng et al. Power system stochastic economic dispatch considering uncertain outputs from plug in electric vehicles and wind generators J. Automation of Electric Power Systems, 2010, 34(20):22-29.

[4]. Yu Dayang, Song Shuguang,Zhang Bo, et al. Synergistic dispatch of PEVs charging and wind power in Chinese regional power grids. Automation of Electric Power System, 2011, 35(14):24-29.

[5]. ZHNG Xueqing, LIANG Jun, ZHANG Li, et al. Approach for plug-in electric vehicles charging scheduling considering wind and photovoltaic power in Chinese regional power grids [J] .Transactions of China electrotechnical Society,2013,(2):28-35.

[6]. Taylor M J, Alexander A. Evaluation of the impact of plug-in electric vehicle loading on distribution system operation [C]//IEEE Power \& Energy Society General Meeting. Calgary, Canada: IEEE, 2009:1-6. 